\title{
CORRESPONDENCE
}

\section{THE EVOLUTIONARY PLEXUS}

SIR,-The concept that morphological species must be interpreted in terms of a " plexus of descent " is essential to the understanding of those who would use palaeontological data to further evolutionary theory. Recently I mistakenly credited Trueman with the introduction of this idea (Syst. Assoc. Publ., 2, p. 2). It has been pointed out to me that the concept was first discussed by Swinnerton (Outlines of Palaeontology, 1923). I am sorry I made this mistake, for Swinnerton's textbook has contributed so much to the background thinking of the palaeontologists of to-day that we are apt to forget how many of his ideas were novel when the first edition of the work was published.

Department of Geology,

P. C. Sylvester-Bradley.

UNIVERSITY OF SHEFFIELD.

11th June, 1958.

\section{DEVELOPMENT OF LINEATION IN COMPLEX FOLD SYSTEMS}

SIR,-I have delayed commenting on the paper by Clifford, Fleuty, Ramsey, Sutton, and Watson, (Jan-Feb, 1957) in the hope that someone more familiar with the ground might do so before me. The attempted division of lineation into simple, multiple, and anomalous is admirable but I feel it has (1) led the authors into a compartmentalization which, in many cases, precludes the simple explanation in favour of the complicated. I also think that the paper is in places (2) overwritten, (3) jargon, (4) statistically invalid and (5) of spurious accuracy To deal with these points in order ...

(1) The possibility of rotation simultaneously with, or during the closing stages of folding, does not seem to have been seriously considered. Yet, bent axial traces are shown in figs. 5, 10 and 7. In fig. 5 the clockwise drag of the wrinkles suggests that the wrinkles are related not to the minor fold depicted but to a major one on the "left". In fig. 10 an axial trace concave side south, is crossed by "later" minor folds (whose axial traces are also bent). These features could be explained by clockwise torque (Mead 1920, or Billings 1954). For fig. 7 a similar explanation might also be applicable. Thus Clifford's lineations might be not two separate generations, but merely early and late lineations of the same generation. Rotation and direction of rotation might be established by the minor folding. (Incidentally if the Tarvie fold trace of fig. 7 were folded by the late antiform, surely the early lineation would plunge away from the antiform trace and not toward it ?)

(2) Many expressions hang. In what sense (vertical, lateral, philosophic) is a hinge, hinge line, turn over, used ? Why not also whip-around, turnaround, flop-over, stretch-out? Why 26 words (top p. 16) to tell us that a fold plunges steeply? What is the purpose of fig. 9?

(3) Antiform and synform, uncommon terms to geologists outside Scotland and Scandinavia, are not defined. The references do not help either. An antiform, presumably resembles an anticline. On page 7 , Sutton and Watson mention the arching of an axial plane to produce an antiform. But Ramsay (fig. 6) shows axial traces of antiform and synform without showing the structures which have been arched to produce them. He goes on to speak of minor folds-but what is the relationship of these minor folds and the (presumably earlier) anticlines and synclines? In fig. 8, Ramsay shows superimposed antiforms and synforms but shows no lithologic horizons nor anything so elementary as an anticline or syncline.

(4) Fig. 10 seems statistically invalid. A fold may have any number of axes. And presumably because the axial trace is bent, each axis would be bent. However Fleuty speaks of the fold axis ; does not show the distribution of the $\mathbf{2 5 0}$ foliation readings; gives no indication of the scatter, and does 
not show the "centroid" (point of emergence of his theoretical fold axis) on the map. The bent axial trace is blithely represented as an undistorted plane (fig. $10 \mathrm{c}$ ), and, to make matters more interesting, the centres of all stereo-nets are omitted.

(5) Fig. 8, a map of country where variation in dip is extreme, shows dip symbols of $31^{\circ}, 59^{\circ}, 71^{\circ}$, etc. If these figures represented the average of several readings, they might be valid. Otherwise, only a combination of portable diamond saw, bubble-type clinometer, and several man-months of labour could yield results of such accuracy.

I realize that these remarks are in some ways unfair, as they apply to many other workers. However a serious attempt should be made to fit together field data before separating them by time barriers. Finally the stereographic projection is essentially a mode of presentation. Sometimes it can solve geological problems. It can also be used as window-dressing.

\section{Patrick Arthur Hill.}

\section{REFERENCES}

Billings, M. P., 1954. Structural geology. 2nd Ed. Prentice-Hall, 228.

MEAD, W. J., 1920. Notes on the mechanics of geologic structures. Jour. Geol. xxxiii, 505-523.

DePARTMENT OF GEOLOGY,

CARLETON UNIVERISTY,

Ottawa, Canada.

20 th June, 1958. 